\title{
Assessing Patient Preferences for Treatment Decisions for New Direct Acting Antiviral (DAA) Therapies for Chronic Hepatitis C Virus Infections
}

\author{
Tania M. Welzel • Min Yang • Gautam Sajeev • Yaozhu J. Chen • \\ Brett Pinsky · Yanjun Bao (D) Eric Q. Wu - Douglas Dieterich
}

Received: April 3, 2019 / Published online: June 25, 2019

(C) The Author(s) 2019

\section{ABSTRACT}

Introduction: The new direct acting antiviral (DAA) therapies are able to effectively treat chronic hepatitis $\mathrm{C}(\mathrm{CHC})$. This study elicited the preferences of $\mathrm{CHC}$ patients for treatment attributes of new DAAs.

Methods: An online discrete choice experiment survey was designed to collect data from adult CHC patients in the USA, UK, France, Germany, Spain, and Italy. Patients were asked to choose from alternative hypothetical DAA options, defined by differing levels of nine attributes [i.e., treatment duration, tablet count and packaging, cure rate, required office visits when on treatment, modifications to statins or to proton pump inhibitors (PPIs), and risks of diarrhea, headache and nausea]. Logistic

Enhanced Digital Features To view enhanced digital features for this article go to https://doi.org/10.6084/ m9.figshare.8241509.

T. M. Welzel

J. W. Goethe University, Frankfurt, Germany

M. Yang · G. Sajeev · E. Q. Wu

Analysis Group, Inc., Boston, MA, USA

Y. J. Chen · B. Pinsky · Y. Bao (ه)

AbbVie Inc., North Chicago, IL, USA

e-mail: carol.bao@abbvie.com

D. Dieterich

Mount Sinai, New York, NY, USA regression was used to assess preference for the treatment options.

Results: A total of 328 patients with $\mathrm{CHC}$ completed the survey (USA, $n=227$; European countries, $n=101)$, with a mean age of 47.7 years $(\mathrm{SD}=14.4)$ and an average 11.2 years since CHC diagnosis; $51 \%$ of patients were female. More than half $(60 \%)$ of the patients had treatment for CHC. Patients significantly preferred a DAA regimen with higher cure rate, shorter treatment duration, lower risks of diarrhea, headache, and nausea (all $p<0.001$ ), reduced need for office visits when on treatment $(p=0.044)$, and without requiring dose reduction or timing change in PPIs $(p=0.032)$. Tablet counts were not found to be statistically significant.

Conclusion: Given the overall high cure rates of new DAAs, CHC patients' preferences for therapy may be influenced by treatment attributes other than cure rates and tolerability. Treatments that are more convenient and require less disruption to their daily life (e.g., shorter treatment duration, no modification in PPI use, and fewer office visits when on treatment) are important to patients with $\mathrm{CHC}$ and should be considered when making treatment decisions.

Funding: AbbVie. 
Keywords: Chronic hepatitis C virus; DDA; Direct acting antiviral therapies; HCV; Infectious diseases; Patient preferences

\section{INTRODUCTION}

Hepatitis $C$ is a type of blood-borne viral infection [1] affecting more than 185 million people worldwide $[2,3]$. The majority $(75-85 \%)$ of patients infected with hepatitis $\mathrm{C}$ virus (HCV) develop chronic hepatitis $\mathrm{C}$ (CHC), which is associated with an increased risk of extrahepatic complications such as type 2 diabetes mellitus, cardiovascular disease, and chronic kidney disease, as well as many potentially life-threatening hepatic complications $[1,2,4]$.

The main goal in the treatment of $\mathrm{CHC}$ is to achieve sustained virologic response (SVR), defined as an undetectable or unquantifiable level of HCV RNA at 12-24 weeks after completing treatment $[5,6]$. When patients achieve sustained virologic response, they are considered clinically cured of CHC. Over the past decade, the use of direct acting antiviral agents (DAAs) combined with pegylated interferon alpha and ribavirin $(\mathrm{P} / \mathrm{R})$ has significantly advanced the management of CHC $[5,7,8]$. Since 2013, the approval of the first all-oral interferon-free DAAs has expanded the treatment options for $\mathrm{CHC}$ providing ease of use, favorable tolerability, and cure rates of $90 \%$ or higher in some HCV genotypes [6, 7, 9]. More recently, newer-generation all-oral interferonfree DAAs have further extended these clinical benefits to $\mathrm{CHC}$ patients with all $\mathrm{HCV}$ genotypes [7].

While sustained virologic response (i.e., cure rate) and tolerability remain the core outcomes of interest, given comparable high cure rates demonstrated both in clinical trials [10-13] and in the real-world setting [14-16], it is of value to know what other attributes, such as dosing schedule, may influence therapy decisions from the patient's perspective. These conveniencerelated attributes, which may interfere with a patient's daily routine, might very well play a key role given their potentially positive impact on adherence and clinical outcomes [16]. Given the increasing focus on patient-centered care, it is important to appreciate the value that patients place on CHC treatment attributes pertaining to benefits and risks to allow other key stakeholders (e.g., physicians, payers, policymakers) to take into account the patients' perspective and more meaningfully contribute to shared decision-making $[17,18]$. To shed light on this issue, we conducted a multicountry survey study eliciting the preferences of $\mathrm{CHC}$ patients for attributes of new DAAs.

\section{METHODS}

\section{Study Population}

Study participants consisted of adult patients with self-reported CHC in the USA and five European countries (UK, France, Germany, Spain, and Italy). All patients were existing panel members of a well-established market research firm, Survey Sampling Internal (now Dynata), with a global presence for healthcare surveys. To be eligible for the study, patients were required to be at least 18 years old, have a self-reported diagnosis of $\mathrm{HCV}$ infection based on one of the following diagnostic assessments (blood test, liver biopsy, liver ultrasound scan, computed tomography scan, magnetic resonance imaging, or Home Access Hepatitis C Check kit), and have at least 6 years of school education. The targeted sample size was 300 participants, based on the empirical recommendation by the International Society for Pharmacoeconomics and Outcomes Research (ISPOR) Good Research Practices for Conjoint Analysis Task Force [19]. Each study participant consented to participation in the study prior to proceeding to complete the survey questions and was compensated with panel points in the amount that was equivalent to $\$ 5$ upon completion of the survey. This study was performed in accordance with the Helsinki Declaration of 1964 and its later amendments and was granted an exemption status from a full review by the New England Institutional Research Board in December 2016. 


\section{Survey Design}

A cross-sectional survey was designed to collect information from USA and European patients with $\mathrm{CHC}$ on the participants' characteristics, CHC-related medical history, and preferences for new all-oral CHC treatments. The online survey was pretested through phone interviews with simultaneous online screen-sharing with five patients in the USA to assess the clarity of the questions and the relevance of the treatment attributes (described below) and to evaluate user experience. The final version of the survey was based on the feedback received during these interviews. The survey was developed in English and subsequently translated into French, German, Spanish, and Italian. Translated versions of the survey were reviewed by native speakers to ensure clarity and consistency of the questions. Survey test launch was conducted with data collection from two patients meeting the same set of eligibility criteria for survey in each of the participating countries (a total of ten patients) to confirm the clarity prior to the full launch for data collection.

\section{Participant Characteristics}

When a patient received the invitation to participate in the survey through email, the patient was asked to review the background for the study intent and confirmed voluntary participation before going through the eligibility criteria. After confirming eligibility for participation, the first part of the survey collected information on patient demographics (age, gender, country of origin, level of education, and employment status), comorbidities, CHC medical history (HCV genotype, duration of disease, prior injectable recreational drug use), and treatment history (treatment experience, cure status as reported by a physician, proton pump inhibitors [PPI] and statin use, and the Patient Activation Measure [PAM-13]) [20]. PAM-13 measures a patient's ability to manage own health and healthcare decisions $[20,21]$.

\section{Patient Preferences}

The second part of the survey consisted of questions pertaining to patient preferences for a new oral DAA treatment, designed using the discrete choice experiment (DCE) approach, a well-established and widely used methodology for preference elicitation [22]. The DCE design is frequently used to elicit patient preferences for hypothetical treatment scenarios with alternative options (e.g., treatment A vs. treatment B). Different scenarios are presented in the form of choice cards describing competing levels of attributes for each hypothetical treatment, and survey participants are asked to choose their preferred scenario. An example of choice card used in this study is presented in Fig. 1.

Treatment attributes and levels used in the choice cards were determined on the basis of a targeted literature review of the characteristics of new DAAs, either approved or in clinical development at the time of this study in early 2017. The selected attributes and the associated levels reflected the factors that were most relatable to $\mathrm{HCV}$ patients and most likely played a role in patients' preference for a treatment. The relevance and importance of the attributes and levels were confirmed by the $\mathrm{HCV}$ patients when being debriefed through survey pretests. Broadly, the nine selected attributes can be classified as relating to efficacy, convenience, co-therapy management, and common mild side effects for safety/tolerability, with each attribute having three to four levels (Table 1).

Seventy-two choice cards were generated using the SAS macro DCE package (SAS Institute, Cary, NC, USA) to achieve an orthogonal, balanced, and efficient design [17], assigning two hypothetical treatment scenarios to each choice card (Fig. 1). The 72 choice cards were randomly divided into eight blocks of nine cards each and approximately the same numbers of patients were randomly assigned to respond to one of the blocks. Each block also included two extra choice cards for assessing the test-retest internal validity of patients' responses. These two choice cards had the same pair of treatment options but shown in reverse order (i.e., treatment $\mathrm{A}$ in one choice card was treatment $B$ in the other choice card), with one 


\begin{tabular}{|c|c|c|c|c|}
\hline & \multicolumn{2}{|c|}{ Treatment $\mathrm{A}$} & \multicolumn{2}{|c|}{ Treatment B } \\
\hline Treatment duration & \multicolumn{2}{|c|}{12 weeks } & \multicolumn{2}{|c|}{8 weeks } \\
\hline \multicolumn{5}{|l|}{$\begin{array}{l}\text { Once-daily tablet count and } \\
\text { packaging }\end{array}$} \\
\hline Cure rate & 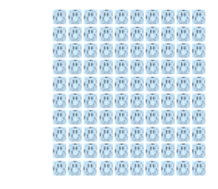 & $\begin{array}{l}100 \% \text { chance } \\
\text { to be cured }\end{array}$ & 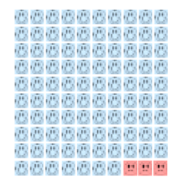 & $\begin{array}{l}97 \% \text { chance } \\
\text { to be cured }\end{array}$ \\
\hline $\begin{array}{l}\text { Follow-up monitoring during } \mathrm{HCV} \\
\text { treatment (all patients are required } \\
\text { to have } 1 \text { visit for treatment } \\
\text { initiation and } 1 \text { visit for post- } \\
\text { treatment evaluation) }\end{array}$ & $\begin{array}{l}\text { Sin } \\
\text { mo } \\
\text { per } \\
\text { tel } \\
\text { do }\end{array}$ & $\begin{array}{l}\text { plified } \\
\text { hitoring (no in- } \\
\text { on visit, eg, } \\
\text { phone check-in by } \\
\text { tor or nurse) }\end{array}$ & 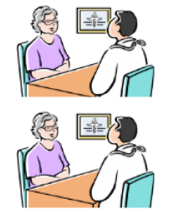 & $\begin{array}{l}2 \text { additional } \\
\text { office visits } \\
\text { during HCV } \\
\text { treatment }\end{array}$ \\
\hline $\begin{array}{l}\text { Modification of concurrent use of } \\
\text { statins (medications to lower } \\
\text { cholesterol level) }\end{array}$ & Temporarily redu & ce dose of a statin & No modifica & ion to a statin \\
\hline $\begin{array}{l}\text { Modification of concurrent use of } \\
\text { PPIs (medications to reduce } \\
\text { stomach acid) }\end{array}$ & $\begin{array}{r}\text { Temporarily redu } \\
\text { timing o }\end{array}$ & $\begin{array}{l}\text { ce dose or modify } \\
\text { taking a PPI }\end{array}$ & No modific & tion to a PPI \\
\hline Risk of diarrhea & 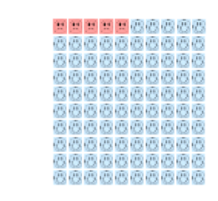 & $\begin{array}{l}5 \text { out of } 100 \\
\text { people }\end{array}$ & 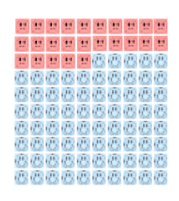 & $\begin{array}{l}25 \text { out of } 100 \\
\text { people }\end{array}$ \\
\hline Risk of headache & 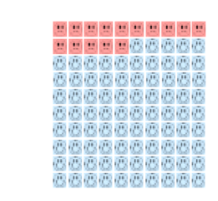 & $\begin{array}{l}15 \text { out of } 100 \\
\text { people }\end{array}$ & 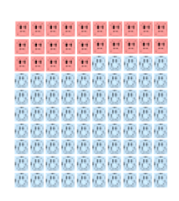 & $\begin{array}{l}25 \text { out of } 100 \\
\text { people }\end{array}$ \\
\hline Risk of nausea & 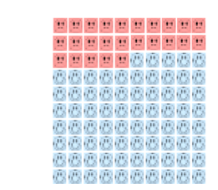 & $\begin{array}{l}25 \text { out of } 100 \\
\text { people }\end{array}$ & 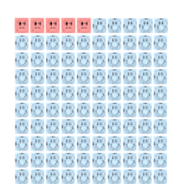 & $\begin{array}{l}5 \text { out of } 100 \\
\text { people }\end{array}$ \\
\hline
\end{tabular}

$H C V$ hepatitis $\mathrm{C}$ virus, $P P I$ proton pump inhibitor

Fig. 1 Example of choice card

treatment designed to be a dominant preferred option over the other treatment.

To ensure that all patients had sufficient background knowledge on CHC treatments and on requirements in the tasks for making a preferred choice decision, a brief tutorial was provided. The tutorial summarized the typical treatment journey of a CHC patient, described the attributes and associated levels of the new oral CHC treatments considered in the survey in plain language, and provided examples of choice cards to familiarize patients with the process of selecting treatment scenarios. 
Table 1 Attributes and levels

Attributes
Efficacy
Cure rate
Convenience
Once-daily tablet count
and packaging

Duration of treatment
(weeks)
Office visits for HCV
treatment (all patients
required to have 1 visit
for treatment initiation
and 1 visit for post-
treatment viral
evaluation)

Co-therapy management

Modification of concurrent statin use $\mathrm{a}^{\mathrm{a}}$

Modification of concurrent PPI use ${ }^{b}$

Mild common side effects

\section{Levels}

95\%; 97\%; 100\%

1 tablet from a prescription bottle

1 tablet in a single-dose blister pack

3 tablets in a single-dose blister pack

$8 ; 12 ; 16 ; 24$

Simplified monitoring during $\mathrm{HCV}$ treatment (e.g., telephone check-in by doctor or nurse)

One additional office visit during $\mathrm{HCV}$ treatment

Two additional office visits during $\mathrm{HCV}$ treatment

No modification to a statin

Temporarily reduce dose of a statin

Temporarily stop taking a statin

Switch to a different medication

No modification to a PPI

Temporarily reduce dose or modify timing of taking a PPI

Temporarily stop taking a PPI

Switch to a different medication
Table 1 continued

\begin{tabular}{ll}
\hline Attributes & Levels \\
\hline Risk of diarrhea & $5 \% ; 15 \% ; 25 \%$ \\
Risk of headache & $5 \% ; 15 \% ; 25 \% ; 35 \%$ \\
Risk of nausea & $5 \% ; 15 \% ; 25 \%$ \\
\hline
\end{tabular}

$H C V$ hepatitis $\mathrm{C}$ virus, PPI proton pump inhibitor

a The levels "temporarily reduce dose of a statin" and "temporarily stop taking a statin" were pooled in the analysis, as they both reflect similar, temporary modifications of use

b The levels "temporarily reduce dose or modify timing of taking a PPI" and "temporarily stop taking a PPI" were pooled in the analysis, as they both reflect similar temporary modifications of use

\section{Statistical Analyses}

Patient demographics, clinical characteristics, and treatment history were summarized using counts and proportions for categorical variables, and means and standard deviations for continuous variables. Multivariable logistic regression models with generalized estimating equations were conducted using SAS 9.4 (SAS Institute, Cary, NC, USA) and used to obtain point estimates and 95\% confidence intervals for the preference weights. Attributes were modeled using dummy coding. Coefficients from the regression analysis were also used to assess the relative importance of treatment attributes in patient preferences.

Subgroup analyses were conducted in patients who self-reported as former or current users of injection drugs, given its high prevalence in $\mathrm{HCV}$ patients. With the test-retest choice card design, patients who made logically consistent choice selections between these two cards were considered to have passed the test-retest assessment. The proportion of patients failing the test-retest assessment of internal validity was documented, and sensitivity analyses limited to those patients who passed the test-retest assessment of internal validity were also conducted. 


\section{RESULTS}

\section{Characteristics of Survey Participants}

Data were collected from 328 adult patients with CHC, 227 (69.2\%) from the USA and 101 (30.8\%) from the five European countries (20 each from the UK, Germany, Spain, and France, and 21 from Italy) in January through March 2017. On average, it took $19 \mathrm{~min}$ for a patient to complete the survey. Patient characteristics are summarized in Table 2. Patients had a mean age of 47.7 years and $51.2 \%$ were female. Most patients had more than 12 years of education $(68.6 \%)$ and $53.7 \%$ of the patients were employed. Approximately half of all patients (49.4\%) were either former or current users of injectable recreational drugs. Among patients who knew their genotype (62.8\%), 35.9\% were genotype $1,24.8 \%$ were genotype $2,27.7 \%$ were genotype $3,10.2 \%$ were genotype $4,1.5 \%$ were genotype 5 , and none were genotype 6 . The selfreported average time since $\mathrm{CHC}$ diagnosis was 11.2 years.

More than half of the patients $(n=197$, $60.1 \%$ ) had prior exposure to or were currently on CHC treatment as of their time of participation in this study in early 2017 (Table 2). Of those who were treatment-experienced, $31.0 \%$ $(n=61)$ had exposure to both interferon-containing and interferon-free treatments and onethird only received interferon-free treatments $(n=68,34.5 \%)$. The most frequently reported chronic comorbidities included anxiety/depression $(45.4 \%)$, cirrhosis or fibrosis $(24.4 \%)$, gastroesophageal reflux disease $(23.5 \%)$, and diabetes/insulin resistance (18.0\%). Approximately $18 \%$ and $20 \%$ of patients were on PPIs and statins, respectively. At the time of the survey, approximately half of the patients were told by their doctors that they were cured of CHC (49.7\%). The majority of the patients $(81.1 \%)$ were motivated, either beginning to take action or having maintained behavior over time in managing their own health. Among the participating patients, $83.2 \%$ patients provided consistent responses to the test-retest questions.
Table 2 Characteristics of survey participants

\begin{tabular}{|c|c|}
\hline & $\begin{array}{l}\text { CHC } \\
\text { patients }^{\text {a }} \\
N=328\end{array}$ \\
\hline Age (years), mean $\pm S D$ & $47.7 \pm 14.4$ \\
\hline Female, $n(\%)$ & $168(51.2)$ \\
\hline \multicolumn{2}{|l|}{ Country/region, $n(\%)$} \\
\hline USA & $227(69.2)$ \\
\hline European countries ${ }^{\mathrm{b}}$ & $101(30.8)$ \\
\hline \multicolumn{2}{|l|}{ Highest level of formal education, $n(\%)$} \\
\hline Completed $6-12$ years of education & $103(31.4)$ \\
\hline Completed $>12$ years of education & $225(68.6)$ \\
\hline \multicolumn{2}{|l|}{ Employment status, $n(\%)$} \\
\hline Employed & $176(53.7)$ \\
\hline Not working & $140(42.7)$ \\
\hline Student & $8(2.4)$ \\
\hline Declined to answer & $4(1.2)$ \\
\hline \multicolumn{2}{|c|}{ HCV genotype among patients reporting genotype $(n=206), n(\%)$} \\
\hline Genotype 1 & $74(35.9)$ \\
\hline Genotype 2 & $51(24.8)$ \\
\hline Genotype 3 & $57(27.7)$ \\
\hline Genotype 4 & $21(10.2)$ \\
\hline Genotype 5 & $3(1.5)$ \\
\hline Genotype 6 & $0(0.0)$ \\
\hline \multicolumn{2}{|l|}{ Time since HCV diagnosis, $n(\%)$} \\
\hline Within the last 1 year & $18(5.5)$ \\
\hline More than 1 year, but less than 3 years & $43(13.1)$ \\
\hline Between 3 and 5 years & $40(12.2)$ \\
\hline More than 5 years & $227(69.2)$ \\
\hline Time since HCV diagnosis (years), mean \pm SD & $11.2 \pm 7.2$ \\
\hline \multicolumn{2}{|l|}{ Treatment history, $n$ (\%) } \\
\hline Treatment-naïve & $131(39.9)$ \\
\hline Treatment-experienced & $197(60.1)$ \\
\hline Told cured by doctor, $n(\%)$ & $163(49.7)$ \\
\hline \multicolumn{2}{|l|}{ Selected key chronic comorbidities, $n$ (\%) } \\
\hline Anxiety/depression & $149(45.4)$ \\
\hline Cardiovascular disease (e.g., ischemic heart disease) & $29(8.8)$ \\
\hline Cirrhosis & $47(14.3)$ \\
\hline Diabetes/insulin resistance & $59(18.0)$ \\
\hline Fibrosis & $33(10.1)$ \\
\hline Gastroesophageal reflux disease & $77(23.5)$ \\
\hline Hepatitis B virus infection & $32(9.8)$ \\
\hline HIV infection/AIDS & $23(7.0)$ \\
\hline Kidney disease & $24(7.3)$ \\
\hline Liver cancer & $17(5.2)$ \\
\hline Liver transplant & $20(6.1)$ \\
\hline
\end{tabular}


Table 2 continued

\begin{tabular}{|c|c|}
\hline & $\begin{array}{l}\mathrm{CHC} \\
\text { patients }^{\mathrm{a}} \\
N=328\end{array}$ \\
\hline \multicolumn{2}{|l|}{ Injectable recreational drug use, $n(\%)$} \\
\hline Never used & $154(47.0)$ \\
\hline Former/current user & $162(49.4)$ \\
\hline Decline to answer & $12(3.7)$ \\
\hline \multicolumn{2}{|l|}{ Concurrent medications, $n(\%)$} \\
\hline Receiving PPIs & $59(18.0)$ \\
\hline Receiving statins & $67(20.4)$ \\
\hline \multicolumn{2}{|l|}{ Patient motivation level (by PAM-13), $n$ (\%) } \\
\hline $\begin{array}{l}\text { Level } 1 \text { (not yet believe patients have active/ } \\
\text { important role) }\end{array}$ & $27(8.4)$ \\
\hline Level 2 (lack confidence/knowledge to take action) & $34(10.6)$ \\
\hline Level 3 (beginning to take action) & $148(46.0)$ \\
\hline Level 4 (maintaining behavior over time) & $113(35.1)$ \\
\hline \multicolumn{2}{|c|}{$\begin{array}{l}H C V \text { hepatitis } \mathrm{C} \text { virus, } H I V \text { human immunodeficiency virus, } A I D S \\
\text { acquired immunodeficiency syndrome, } P P I \text { proton pump inhibitor } \\
\text { a Include patients from the USA and European countries } \\
\text { b UK, France, Germany, Spain, and Italy } \\
\text { c Counts for categorical variables may not sum to } 328 \text { because of } \\
\text { missing data or patients declining to answer certain questions }\end{array}$} \\
\hline
\end{tabular}

\section{Patient Preferences for HCV Treatment}

CHC treatment attributes significantly and strongly preferred by patients were higher cure rate, lower risks for common mild side effects including diarrhea, headache, and nausea, and shorter treatment duration (all $p<0.01$ ) (Table 3). In addition, treatments requiring only one additional visit while on CHC treatment were favored over those requiring two additional visits $(p=0.044)$. Treatments requiring no modification to PPIs were favored over those requiring a temporary dose reduction, change in timing, or temporarily stop in PPI $(p=0.032)$ though patients did not seem to mind changing to a different PPI. Of all attributes considered, two of them were not significant in patients' preference decision towards a new oral $\mathrm{CHC}$ treatment: patients were found to be indifferent between having one tablet or three tablets in terms of pill count and for having modification or change to a different statin vs. no change in statin.

Among the subgroup of patients who selfreported as former or current injectable drug users, treatment attributes preferred were generally similar to the overall patients, with strong preference for higher cure rate, lower side effect risks, and shorter treatment duration. Among these patients, treatments requiring simplified monitoring without in-person office visit $(p=0.023)$ or only one additional office visit $(p=0.084)$ were preferred over those requiring two additional office visits.

As a sensitivity analysis, the model was also run using data from patients who passed the test-retest questions $(N=273 ; 83.2 \%)$. The results were consistent except that all coefficient estimates became stronger and that no inperson visits became also significantly favored over two additional office visits $(p=0.026)$, along with favoring one additional visit over two additional office visits $(p=0.009)$.

\section{Attributes Relative Importance}

The relative importance of the treatment attributes is illustrated in Fig. 2. Overall, cure rate had the highest impact on HCV treatment choice (36\%), followed by side effects (13-19\%), statin and PPI medication management (7\%), treatment duration of 8 weeks instead of 12 weeks $(6 \%)$, and monitoring during treatment (4\%). Pill count had the least impact on preference (1\%). Altogether, convenience attributes were valued more than co-therapy management (11\% vs. $7 \%)$. All other attributes held equal, among the convenience attributes, the 8 -week treatment duration was the most valued by patients when compared to the 12 -week treatment duration (55\%), followed by monitoring involving one fewer visit when compared to two additional office visits (37\%), and tablet counts for 3 vs. 1 (8\%), although the coefficient of pill counts indicates that this attribute does not significantly impact patients' choices in therapies. When we focus entirely on nonclinical attributes, i.e., treatment duration and pill counts, 87 out of 100 patients would prefer the 8-week treatment duration when compared to the 12-week treatment duration (87\%). Thirteen percent of patients would prefer tablet counts, although the coefficient of pill counts indicates that it is not a statistically 
Table 3 Patient preferences for treatment attributes (overall population $^{\mathrm{a}}$ )

\begin{tabular}{|c|c|c|c|}
\hline Treatment attributes & Estimate & 95\% CI & $p$ value \\
\hline \multicolumn{4}{|l|}{ Efficacy } \\
\hline $\begin{array}{l}\text { Cure rate (per \% } \\
\text { change) }\end{array}$ & 0.311 & $\begin{array}{r}(0.267 \\
0.356)\end{array}$ & $<0.001^{*}$ \\
\hline \multicolumn{4}{|l|}{ Convenience } \\
\hline \multicolumn{4}{|c|}{ Treatment duration (per week) } \\
\hline $\begin{array}{l}8 \text { weeks vs. } \\
12 \text { weeks }\end{array}$ & 0.255 & $\begin{array}{c}(0.090 \\
0.419)\end{array}$ & $0.002^{*}$ \\
\hline $\begin{array}{l}16 \text { weeks vs. } \\
12 \text { weeks }\end{array}$ & -0.061 & $\begin{array}{c}(-0.219 \\
0.097)\end{array}$ & 0.447 \\
\hline $\begin{array}{l}24 \text { weeks vs. } \\
12 \text { weeks }\end{array}$ & -0.321 & $\begin{array}{l}(-0.505 \\
\quad-0.138)\end{array}$ & $<0.001^{\star}$ \\
\hline
\end{tabular}

Once-daily tablet count and packaging

\begin{tabular}{|c|c|c|c|}
\hline $\begin{array}{l}1 \text { tablet from a } \\
\text { prescription bottle } \\
\text { vs. } 1 \text { tablet in a } \\
\text { single-dose blister } \\
\text { pack }\end{array}$ & 0.090 & $\begin{array}{c}(-0.035 \\
0.216)\end{array}$ & 0.159 \\
\hline $\begin{array}{l}3 \text { tablets in a } \\
\text { single-dose blister } \\
\text { pack vs. } 1 \text { tablet in } \\
\text { a single-dose blister } \\
\text { pack }\end{array}$ & -0.034 & $\begin{array}{c}(-0.171 \\
0.103)\end{array}$ & 0.624 \\
\hline Visits during $\mathrm{HCV}$ tre & eatments & & \\
\hline $\begin{array}{l}\text { Simplified } \\
\text { monitoring (no in- } \\
\text { person visit, e.g., } \\
\text { telephone checking } \\
\text { in) vs. two } \\
\text { additional office } \\
\text { visits }\end{array}$ & 0.131 & $\begin{array}{c}(-0.036 \\
0.298)\end{array}$ & 0.124 \\
\hline $\begin{array}{l}\text { One additional } \\
\text { office visit vs. two } \\
\text { additional office } \\
\text { visits }\end{array}$ & 0.170 & $\begin{array}{c}(0.005 \\
0.336)\end{array}$ & $0.044^{*}$ \\
\hline
\end{tabular}

Table 3 continued

\begin{tabular}{|c|c|c|c|}
\hline Treatment attributes & Estimate & $95 \% \mathrm{CI}$ & $p$ value \\
\hline $\begin{array}{l}\text { Temporarily } \\
\text { reduce dose or stop } \\
\text { taking vs. no } \\
\text { modification }\end{array}$ & -0.105 & $\begin{array}{c}(-0.249 \\
0.039)\end{array}$ & 0.152 \\
\hline $\begin{array}{l}\text { Switch to a } \\
\text { different } \\
\text { medication vs. no } \\
\text { modification }\end{array}$ & -0.129 & $\begin{array}{c}(-0.296 \\
0.038)\end{array}$ & 0.131 \\
\hline Modification of PPIs & & & \\
\hline $\begin{array}{l}\text { Temporarily } \\
\text { reduce dose/timing } \\
\text { or stop taking vs. } \\
\text { no modification }\end{array}$ & -0.171 & $\begin{array}{l}(-0.326 \\
\quad-0.015)\end{array}$ & $0.032^{*}$ \\
\hline $\begin{array}{l}\text { Switch to a } \\
\text { different } \\
\text { medication vs. no } \\
\text { modification }\end{array}$ & -0.125 & $\begin{array}{c}(-0.298 \\
0.047)\end{array}$ & 0.155 \\
\hline \multicolumn{4}{|c|}{ Mild common side effects } \\
\hline \multicolumn{4}{|c|}{ Risk of adverse events (per \% change) } \\
\hline Diarrhea & -0.033 & $\begin{array}{l}(-0.040 \\
\quad-0.025)\end{array}$ & $<0.001^{*}$ \\
\hline Headache & -0.028 & $\begin{array}{l}(-0.034 \\
\quad-0.022)\end{array}$ & $<0.001^{*}$ \\
\hline Nausea & -0.028 & $\begin{array}{l}(-0.036 \\
\quad-0.019)\end{array}$ & $<0.001^{*}$ \\
\hline
\end{tabular}

${ }^{a}$ All patients from the USA and the five European countries (UK, France, Germany, Spain, and Italy) ${ }^{*} p$ value $<0.05$

significant factor in patients' treatment choice decisions for HCV.

\section{DISCUSSION}

The treatment of $\mathrm{CHC}$ has undergone significant advancement over the past decade. In particular, the cure rate with new DAAs has climbed to over 90\% across genotypes, with some of the newest DAAs achieving a cure rate of $100 \%$ in certain genotypes $[9,23,24]$. Given 

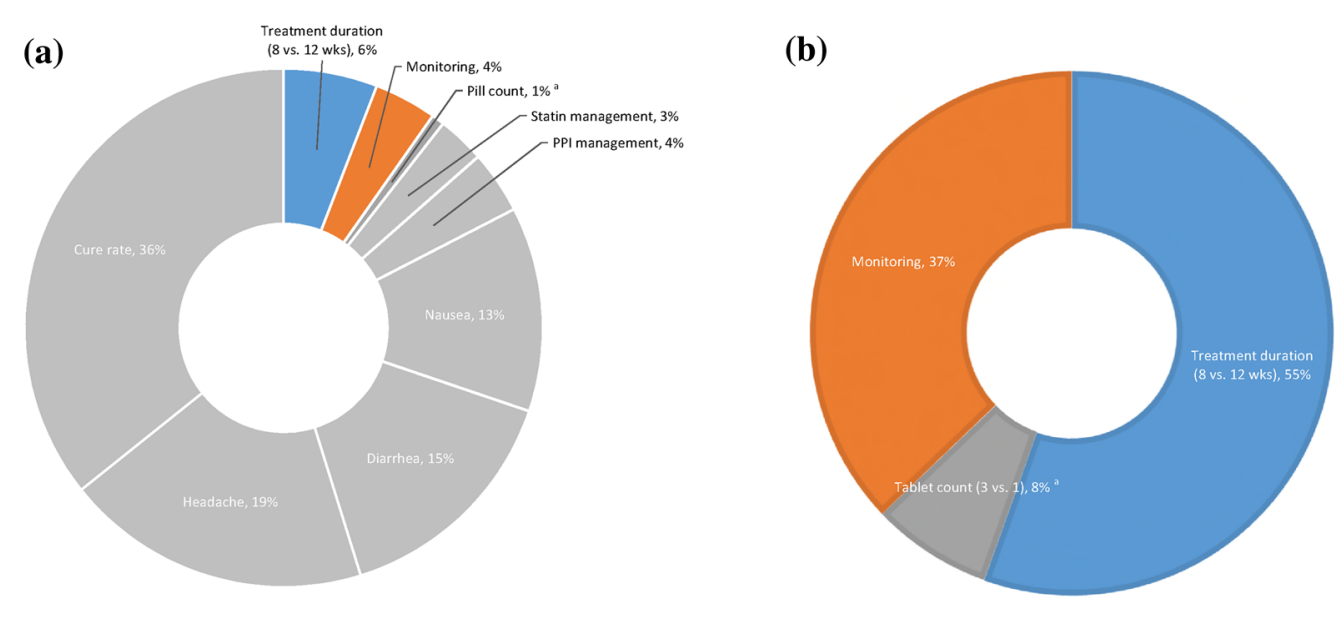

Fig. 2 Relative importance of treatment attributes. a Relative importance of all attributes for all-oral HCV treatment choice. b Relative importance of convenience attributes

that the difference in cure rate for the newest DAAs is relatively small, other treatment characteristics may in turn have a substantial impact on which treatment patients may prefer. This study found that attributes in each of the four categories, i.e., efficacy, safety/tolerability, cotherapy management, and convenience, can play a significant role in patient's preference decisions for CHC treatment. Not surprisingly, the most important treatment attributes were efficacy (i.e., cure rate) and safety/tolerability (i.e., risks of common mild side effects). Cure rate identified as the attribute of a DAA that CHC patients value the most is in line with previous studies [16, 25-28].

Among the remaining attributes for convenience and co-therapy management in the present study, treatment duration (i.e., 8 weeks vs. 12 weeks) was found to be the most important characteristic in preference decision, followed by preferring no modification to temporarily reducing dose/timing or stopping taking PPI, and having one, instead of two, additional office visits. Among all attributes and levels considered, having three tablets once daily vs. one tablet once daily was the least important and not a significant factor in patients' preference for a CHC treatment. With all other attributes held equal and if patients were to choose between the two non-clinical attributes of treatment duration and tablet counts, 87 out of 100 patients will choose a therapy with a shorter treatment duration of 8 weeks vs. 12 weeks.

The findings on the monitoring attribute were also worth noting. While patients strongly preferred having one additional office visit over two additional office visits during their $\mathrm{HCV}$ treatment, the least preferred option was having no in-person office visits at all and only talking with a physician or a nurse over the phone. We speculate that it is possible while patients appreciate the opportunity to reduce interruptions to their daily life (e.g., due to an additional visit to their physician, instead of two), they feel more comfortable with not altogether eliminating in-person physician visits while on treatment. This could be a reasonable consideration, given that many patients with $\mathrm{CHC}$ had various types of comorbidities. In our study, nearly half of the patients reported having anxiety or depression. Patients who had cotherapy such as statin or PPI to manage their blood cholesterol level or gastric reflux problem could require modification to those therapies and thus might also prefer to see their physician to ensure their treatments are being managed appropriately. Interestingly, patients who selfreported as current or previous injection drug users had stronger preferences for having none or one fewer visit rather than two visits, suggesting that these patients may prefer fewer in- 
person visits and consider phone-based monitoring sufficient for management of their $\mathrm{HCV}$ treatment.

In a treatment landscape where an increasing number of new pan-genotypic DAAs may offer the same or similar high cure rates, policymakers' consideration for insurance coverage and reimbursement decisions and physicians' prescribing decisions are likely to increasingly rely on patient preferences. A better understanding of patient preferences is also key to designing future DAAs that may further enhance patients' adherence to the CHC therapy and thus improve clinical outcomes of the treatment. Indeed, DAAs that offer patients greater ease of use, convenience, and better safety profiles are likely to result in increased adherence $[29,30]$. Financial burden associated with medical services in general and pharmaceutical products specifically has drawn increasing attention in recent years. Our study did not include costs of treatment as an attribute because out-of-pocket costs vary substantially within the USA (e.g., government payer vs. commercial payers) and across the countries along with the currency difference. Moreover, costs are more an extrinsic factor; the current study focus was on attributes relating specifically to patients' day-to-day experience of these treatments that would be consistent across regions.

Some limitations should be considered when evaluating the results of this study. First, as a general limitation of all preference research, the preferred choices that patients made in the DCE exercise may not represent their actual $\mathrm{CHC}$ treatment decisions in the real world. Second, the patients who participated in the survey were part of existing market research panels, patients were recruited on the basis of self-reported $\mathrm{CHC}$, and the study was completed through online survey. The findings of this study may not be fully generalizable to the broader CHC patient population though efforts were made so that this study included participants from six countries, including the USA and five European countries. Third, recall bias of disease and treatment-related medical history may have been present. We attempted to minimize this potential bias by providing patients with background information on $\mathrm{CHC}$ and treatment through a mini tutorial. Lastly, factors independent of attributes of a treatment may also impact on the preference decision of the patients, such as patients' knowledge of $\mathrm{CHC}$, experiences with prior $\mathrm{CHC}$ treatments, and the financial burden associated with a treatment. These are not the focus of the current study but should be considered in future research.

\section{CONCLUSIONS}

Given the overall high cure rates achieved by the latest generation of the new all-oral DAAs, patients with $\mathrm{CHC}$ may prefer one treatment over another on the basis of attributes other than cure rate. Indeed, besides cure rate and safety/tolerability, the treatment attributes valued most by patients are added convenience and no or less disruption to their daily routine (i.e., shorter treatment duration, one fewer office visits during treatment, and no modification of PPI use). It is interesting to find that patients are not at all concerned about the number of tablets for a once-daily oral medication while less time spent on managing their disease, be it fewer encounters with healthcare system or an 8-week treatment duration instead of 12 , is most valued. The results of this study provide a better understanding of patient preferences for the attributes of newer-generation DAAs and may improve the efficiency in the shared decision-making process when managing these patients.

\section{ACKNOWLEDGEMENTS}

The authors wish to thank the contribution from all of the study participants.

Funding. Sponsorship for this study, the journal's article processing charges, and open access fee were funded by AbbVie. All authors had full access to all of the data in this study and take complete responsibility for the integrity of the data and accuracy of the data analysis. The design, study conduct, and financial 
support for the study were provided by AbbVie (Grant no. 1). AbbVie participated in the interpretation of data, review, and approval of the publication.

Authorship. All named authors meet the International Committee of Medical Journal Editors (ICMJE) criteria for authorship for this article, take responsibility for the integrity of the work as a whole, and have given their approval for this version to be published.

Medical Writing, Editorial, and Other Assistance. Medical writing assistance was provided by Cinzia Metallo, PhD, an employee of Analysis Group, Inc. The authors wish to thank David Kinrich and Yao Wang, employees of Analysis Group, Inc., for conducting statistical analysis for the study. AbbVie provided funding for this work.

Prior Presentation. This manuscript was based on a poster that was previously presented at the American Association for the Study of Liver Disease 68th Annual Meeting, October 20-24, 2017, Washington, DC. Additional analysis was conducted for the manuscript as well.

Disclosures. Tania M. Welzel is a member of advisory committees or review panels for Novartis, Janssen, Gilead, AbbVie, BoehringerIngelheim, and BMS. Brett Pinsky is a stock shareholder and employee of AbbVie. Yanjun Bao is a stock shareholder and employee of AbbVie. Yaozhu J. Chen was an employee of AbbVie until September 2018 and owns stocks of Abbvie. Min Yang is an employee of Analysis Group, Inc., which has received consultancy fees from AbbVie for this study. Gautam Sajeev is an employee of Analysis Group, Inc., which has received consultancy fees from AbbVie for this study. Eric Q. Wu is an employee of Analysis Group, Inc., which has received consultancy fees from AbbVie for this study. Douglas Dieterich has served as a consultant to AbbVie, and has received research funding and speaker fees from AbbVie.
Compliance with Ethics Guidelines. This study was performed in accordance with the Helsinki Declaration of 1964 and its later amendments and was granted an exemption from a full review by the New England Institutional Research Board. All survey participants consented to participation in the study prior to proceeding to completing the survey questions.

Data Availability. This manuscript has no associated data or the data will not be deposited.

Open Access. This article is distributed under the terms of the Creative Commons Attribution-NonCommercial 4.0 International License (http://creativecommons.org/licenses/ by-nc/4.0/), which permits any noncommercial use, distribution, and reproduction in any medium, provided you give appropriate credit to the original author(s) and the source, provide a link to the Creative Commons license, and indicate if changes were made.

\section{REFERENCES}

1. Webster DP, Klenerman P, Dusheiko GM. Hepatitis C. Lancet. 2015;385:1124-35.

2. Tyagi I, Koirala J. Hepatitis C. Treasure Island: StatPearls. https://www.ncbi.nlm.nih.gov/books/ NBK430897/. Accessed Sep 2018.

3. Denniston MM, Jiles RB, Drobeniuc J, et al. Chronic hepatitis $C$ virus infection in the United States, National Health and Nutrition Examination Survey 2003 to 2010. Ann Intern Med. 2014;160:293-300.

4. Younossi Z, Park H, Henry L, Adeyemi A, Stepanova M. Extrahepatic manifestations of hepatitis C: a meta-analysis of prevalence, quality of life, and economic burden. Gastroenterology. 2016;150:1599-608.

5. Smith-Palmer J, Cerri K, Valentine W. Achieving sustained virologic response in hepatitis C: a systematic review of the clinical, economic and quality of life benefits. BMC Infect Dis. 2015;15:19.

6. Terrault NA, Hassanein TI. Management of the patient with SVR. J Hepatol. 2016;65:S120-9. 
7. Kish T, Aziz A, Sorio M. Hepatitis C in a new era: a review of current therapies. Pharm Ther. 2017;42:316-29.

8. Kohli A, Shaffer A, Sherman A, Kottilil S. Treatment of hepatitis C: a systematic review. JAMA. 2014;312:631-40.

9. Horner SM, Naggie S. Successes and challenges on the road to cure hepatitis C. PLoS Pathog. 2015;11:e1004854.

10. Zeuzem S, Foster GR, Wang S, et al. Glecaprevir-pibrentasvir for 8 or 12 weeks in HCV genotype 1 or 3 infection. N Engl J Med. 2018;378:354-69.

11. Forns X, Lee SS, Valdes J, et al. Glecaprevir plus pibrentasvir for chronic hepatitis $\mathrm{C}$ virus genotype $1,2,4,5$, or 6 infection in adults with compensated cirrhosis (EXPEDITION-1): a single-arm, open-label, multicentre phase 3 trial. Lancet Infect Dis. 2017;17:1062-8.

12. Foster GR, Afdhal N, Roberts SK, et al. Sofosbuvir and velpatasvir for HCV genotype 2 and 3 infection. N Engl J Med. 2015;373:2608-17.

13. Feld JJ, Jacobson IM, Hezode C, et al. Sofosbuvir and velpatasvir for HCV genotype 1, 2, 4, 5, and 6 infection. N Engl J Med. 2015;373:2599-607.

14. D'Ambrosio R, Pasulo L, Puoti M, et al. Real-world effectiveness and safety of glecaprevir/pibrentasvir in 723 patients with chronic hepatitis C. J Hepatol. 2019;70(3):379-87.

15. Belperio PS, Shahoumian TA, Loomis TP, Mole LA, Backus LI. Real-world effectiveness of daclatasvir plus sofosbuvir and velpatasvir/sofosbuvir in hepatitis C genotype 2 and 3. J Hepatol. 2019;70:15-23.

16. Muhlbacher A, Bethge S. First and foremost battle the virus: eliciting patient preferences in antiviral therapy for hepatitis $\mathrm{C}$ using a discrete choice experiment. Value Health. 2016;19:776-87.

17. Reed Johnson F, Lancsar E, Marshall D, et al. Constructing experimental designs for discrete-choice experiments: report of the ISPOR conjoint analysis experimental design good research practices task force. Value Health. 2013;16:3-13.

18. FDA. Advancing use of patient preference information as scientific evidence in medical product evaluation. https://www.fda.gov/ScienceResearch/ SpecialTopics/RegulatoryScience/ucm574320.htm. Accessed Sep 2018.

19. Bridges JF, Hauber AB, Marschal D, et al. Conjoint analysis applications in health-a checklist: a report of the ISPOR good research practices for conjoint analysis task force. Value Health. 2011;14:403-13.

20. Hibbard JH, Mahoney ER, Stockard J, Tusler M. Development and testing of a short form of the patient activation measure. Health Serv Res. 2005;40:1918-30.

21. Hibbard JH, Stockard J, Mahoney ER, Tusler M. Development of the patient activation measure (PAM): conceptualizing and measuring activation in patients and consumers. Health Serv Res. 2004;39:1005-26.

22. Ho M, Saha A, McCleary KK, et al. A framework for incorporating patient preferences regarding benefits and risks into regulatory assessment of medical technologies. Value Health. 2016;19:746-50.

23. Su F, Beste LA, Green PK, Berry K, Ioannou GN. Direct-acting antivirals are effective for chronic hepatitis $C$ treatment in elderly patients: a realworld study of 17,487 patients. Eur J Gastroenterol Hepatol. 2017;29:686-93.

24. Dalgard O, Weiland O, Noraberg G, et al. Sofosbuvir based treatment of chronic hepatitis $C$ genotype 3 infections-a Scandinavian real-life study. PLoS One. 2017;12:e0179764.

25. Evon DM, Golin CE, Stoica T, et al. What's important to the patient? Informational needs of patients making decisions about hepatitis $\mathrm{C}$ treatment. Patient. 2017;10:335-44.

26. Zuchowski JL, Hamilton AB, Pyne JM, et al. Qualitative analysis of patient-centered decision attributes associated with initiating hepatitis $\mathrm{C}$ treatment. BMC Gastroenterol. 2015;15:124.

27. Kauf TL, Mohamed AF, Hauber AB, Fetzer D, Ahmad A. Patients' willingness to accept the risks and benefits of new treatments for chronic hepatitis C virus infection. Patient. 2012;5:265-78.

28. Muhlbacher AC, Bridges JF, Bethge S, et al. Preferences for antiviral therapy of chronic hepatitis $C$ : a discrete choice experiment. Eur J Health Econ. 2017; 18:155-65.

29. Re VL, Amorosa VK, Localio AR, et al. Adherence to hepatitis $C$ virus therapy and early virologic outcomes. Clin Infect Dis. 2009;48:186-93.

30. Jeong SW, Kim JD, Woo HY, et al. Impact of adherence to peginterferon-ribavirin combination therapy in chronic hepatitis $\mathrm{C}$ patients on achieving a sustained virologic response. Korean J Hepatol. $2009 ; 15: 338-49$. 